\title{
Strategies To Make Remote Learning More Engaging
}

\author{
Umida Khaydarova, Sultankulov Gayrat
}

Foreign languages department Tashkent State University of Law, Uzbekistan

\begin{abstract}
The introduction of modern information and communication technologies in the educational process, in addition to traditional teaching methods, has led to the transition to a new form of teaching - distance learning. Methods of distance learning and interactive methods are given. Recommendations are given to bring the education system in this direction, taking into account modern technology.
\end{abstract}

Keywords:

distance education, information and communication, interactive education, information technology, e-learning textbook.

Article Received: 18 October 2020, Revised: 3 November 2020, Accepted: 24 December 2020

\section{INTRODUCTION}

At the end of the twentieth century, humanity faced a number of problems, which are directly related to significant changes in the field of information and telecommunications, in particular, the rapid development of information technology. New means of information and communication began to enter various spheres of education and production. The development of the global computer network, the Internet, has opened up new avenues for improving the education system around the world. First, the drastic changes in the technical equipment of educational institutions, the opening of wide access to secular information resources have led to the need to use new forms and methods of teaching.

No doubt, the switch to remote learning has changed many aspects of how we live, work and learn. I believe the same holds true for our teaching pedagogy - it needs to evolve. Our students are accustomed to a world of their own design. To teach them, I believe we will need to meet them halfway. With both the availability and the capabilities of today's technology, it's on us to prepare ourselves with engaging lessons.

It is becoming increasingly clear that the education system of our country is undergoing significant changes. It is gratifying that distance learning, along with other forms of education, is becoming more widespread.
It is well known that this method has many advantages. All higher education institutions are working on the implementation of distance learning techniques and technologies. The development of information technology requires a new approach to the organization of distance learning. Modern models of distance learning are based on communication and network technologies. While these technologies provide users with a wide range of information, they also pose a challenge to their protection.

Lack of direct communication between teacher and listener in distance learning also causes some problems. For example, there are certain difficulties in organizing a problem-based learning process. Problem-based learning in the training of listeners as professionals can be achieved through teleconferencing. However, this does not completely solve the problem. Additional training materials will be required to address this issue. These should include different levels of problem assignments, problem-solving instructions, and so on.

It is a requirement of the time to train a specialist who fully meets the requirements of modern times. At present, a lot of positive work is being done in our country to educate, train, educate the younger generation, to approach modern information technologies and to teach them to work with new techniques and technologies. The most 
important of these is Distance Learning Techniques and Technology. In this regard, the steps to prepare the younger generation for distance learning can be implemented as follows:

In today's world of information technology, distance learning is becoming increasingly important. Because this type of education differs from the existing ones in some respects. The difference between distance learning and full-time education is that it can involve a wide range of people. Distance learning combines the positive features of full-time and part-time education. In this regard, distance learning is one of the most promising forms of education today.

It is not necessary to gather a certain part of the population who want to study at the location of the educational institution for distance learning. Second, there is no need for the listener or student to overspend. Third, the age limit for those involved in this type of education can be excluded. The contingent involved in distance learning can be made up of people from the following social groups:

In the context of Uzbekistan, the organization of distance learning is very effective. This type of education should be widely used today. It is natural that there are some problems with the introduction of this type of education. But they can be resolved at the level of opportunity. For example, using television in the beginning can be very effective. Some subjects are now being taught on television. But the show has seemed a bit unfocused in recent episodes. First of all, these shows are mostly during the day. Second, its methodology needs to be further improved. If distance learning is to be organized on the basis of these trainings, then it is necessary to reconsider the organizational and methodological aspects of this type of education.

As mentioned above, distance learning combines the features of full-time and part-time education. Therefore, some elements of distance learning can be used in its organization. In the 80's of the last century, part-time training courses were organized to prepare applicants for entrance exams. Course staff mailed to the applicant options for tasks and assignments developed by specialists in the relevant disciplines. The assignments and assignments that the entrant was sent to the course address for review within a certain period of time were to be reviewed by the instructor and notified to the applicant with brief comments.

In distance education, the learner and the teacher are in constant communication with each other through spatially separated learning courses, forms of control, electronic communication and other technologies of the Internet. Distance learning based on the use of Internet technology provides access to the global information education network.

Interactive teaching, the effectiveness of distance learning platforms, the formation of elearning materials, the tasks and design of the learning cycle have been developed. Technologies aimed at improving comprehension and memory were used, and the methodology and software needed to create an effective presentation, including a video presentation, were selected.

Currently, on the basis of materials created by professors and teachers of the Institute, distance learning courses are conducted for inspectors of organizational departments of regional law enforcement agencies, and employees are trained offline by distance. With the help of the login and password given to the listeners, they were able to use the personal account of the system and electronic resources in the system through the official website of the Institute.

The training process is designed for a period of one month on the basis of 4 modules, in which students independently master the relevant teaching resources in the system of distance learning in real time. In this case, a system of entrance tests for students to start the course, exercises, tests and other assignments are given for them to master the topics.

- Distance learning allows listeners and teachers to communicate remotely.

- Today, social life is developing rapidly. The effective use of advanced innovative information technologies in improving the knowledge of employees in the system of law enforcement 
agencies, as well as in all spheres of social life, has become a requirement of today.

Different information and communication technologies are used in distance learning. For example, while traditional print-based teaching aids (textbooks, manuals) are based on introducing students to new material, interactive audio and video conferencing allows them to interact with each other over a period of time. It is designed to communicate and receive feedback, ie to send and receive messages. While pre-taped video lectures allow students to listen and watch lectures, facsimile communication, messages, and the rapid exchange of assignments over the network allow students to teach through feedback.

Based on the above, we give a description and definitions of some terms related to the educational process.

Distance education is education based on distance learning.

Distance learning - a distance between the learner and the teacher based on Internet technology or other interactive methods and components of all learning processes - goals, content, methods, organizational forms and teaching methods The relationship between.

Distance learning system is a system of education based on the conditions of distance learning. Like all education systems, the distance learning system has its own purpose, content, methods, tools and organizational forms. Pedagogical technologies of distance learning is a set of teaching methods and techniques that provide the educational process of distance learning based on the selected concept of teaching. The Center for Professional Development of the Institute is working to introduce distance learning at the Institute.

One of the most important issues in the organization of distance learning is the selection of professors and teachers. In order to implement this type of education, teachers must be selected from the most experienced and organized professors. Because distance learning is different from other types of education, its effectiveness depends in many ways on the knowledge, organization and management of the teacher. Because a teacher involved in distance learning must be a skilled educator, a wise counselor and an experienced manager at the same time. At the initial stage of the organization of distance learning, based on the demographic characteristics of the population of the republic, it is necessary to create distance learning points in the relevant regional or regional centers. The structure should be responsible for the organization of distance learning in the field. In the next stages, Distance Learning Centers may be established in several higher education institutions specializing in one or more different areas.

It is well known that the role of modern information technologies and systems in the gradual implementation of the goals and objectives of the Law of the Republic of Uzbekistan "On Education" and the "National Training Program" is important. Modern information technologies: multimedia, translation from one language to another, conversion from one alphabet to another, computer test control, scanning technology, internet, email, Web technology, electronic virtual library, distance learning, presentation technology, artificial thinking systems, etc.

Given the noble goals of the full implementation of the "National Training Program", it is easy to see that today the need for the use of advanced technologies in each area of education is particularly relevant.

We have all witnessed that the involvement of modern information technologies in the education system, which is an important need for the development of our daily lives and prospects, is becoming increasingly important. This can be seen in the example of many special education institutions, academic lyceums, professional colleges and leading universities and academies, which today spend a lot of time to change the educational process, for example, the effectiveness of education. it is unimaginable without multimedia tools, which manifest in a sharp contraction and a sharp increase in the retention of knowledge in memory.

Step 1. This stage is called the "Meeting Stage" for the children. At this stage, the main problem is the 
provision of computers in existing preschools in the country.

Preschools will have to teach the younger generation fun programs such as games, cartoons, calculators, arithmetic, children's encyclopedias that teach a variety of programs, and children's music for recreation.

Step 2. This is especially true for those who have a computer in their family. Currently, most households in the country have a computer. That is why this stage can be called the "Renaissance stage".

Step 3. At this stage, students of schools, lyceums, vocational colleges and others will have access to a full computer system. That is why this stage can be called the "adaptation" stage.

Step 4. At this stage, the student should be able to work fully with the computer. The student is ready to develop a generation of computers, what language to write, what programming language to work with, what operating systems to work with, printers, scanners, modems, fax modems, computer networks, including the Internet, e-library and elearning manuals will be. That is why this stage can be called the "Independent Work and Thinking" stage.

Step 5. At this stage the specialist will be ready. This stage can be called the "maturity" stage. During the development phase, professionals will be able to manage their work in their field directly, without hesitation, within the enterprise, organization, institution and firm.

There are some problems with the implementation of the above steps, namely:

a) computerization of children's pre-school education institutions;

\section{b) Provide schools with full computers.}

It is no exaggeration to say that professional colleges and universities in our country are fully equipped with modern information technologies. These are, of course, the conveniences and conditions for creating the next generation for distance learning.

Distance learning is also part-time, with only teacher-student communication using computers, telecommunications devices, and the Internet. During the training, the student receives training materials and assignments on his computer, sends the completed tests and tests to the teacher via the Internet or e-mail. In addition, the listener can ask questions to his teacher and methodologist and get timely answers. Measures have been developed to organize distance learning and implement it in the educational process. According to the plan of the event, the work on the organization of distance learning at the institute is divided into four areas: Organizational and educational work with distance learning participants.

Get acquainted (gain, obtain) with information and telecommunication technologies used in distance education, and work on creating a computer and software package with the necessary technical capabilities. Work on the development of teaching materials for distance learning. Study and introduction of technology of educational materials used in distance learning. The society under construction must become an information society in the 21 st century. In this way, the promotion of information literacy, including economic and legal literacy, will spread widely among the people of our spiritual society. In this case, interactive education comes into force, and, consequently, the pedagogy of this education is formed.

Interactive learning is a distance learning method, communication, as well as a number of interactive (audio, video, electronic conferences, television and voice communications, interaction via satellite, etc.) that implement this method. and using noninteractive technologies. The role of the Internet in popularizing interactive distance learning, the role of telecommunications, an excellent corridor for equal access to the Internet for all, the scientist who created the WWW (Web) technology Tim Berners. Lee's service is invaluable.

There are many online education databases around the world, including the database of the Global Distance Learning Center at the British Open University. There is an International Distance Learning Council and the number of D-Learners is growing day by day. 
It should be noted that many of the advantages of distance learning, such as creativity in learning, the ability to study independently, the freedom to allocate time for learning, are reflected in the pedagogical research of leading scientists in our country.

It is gratifying that in our country the intelligentsia, including teachers, everyone who is not indifferent to the upbringing of a new generation, especially young students, show great interest and desire for interactive learning using modern computer and telecommunication technologies, in particular, online education, the Internet.

As Uzbekistan is building a strong state with a strong economy and a promising rule of law, improving information literacy and legal culture of our people is a requirement of life and time. To achieve this goal, it is necessary to launch interactive education, the foundations of which are already being laid. Distance learning explains two main approaches to learning - expansion and transformation models. The learning technology in the extended model is practically indistinguishable from the current traditional method.

The transformation model includes information and communication technology tools for teacher and student collaboration. These modern methods and technologies of distance learning have introduced new concepts and terms into the pedagogy of theoretical and practical education, such as a virtual classroom, educational telecommunication projects, coordinator, feedback, moderator, communication technologies, computer communication, teleconferences. The technology is almost entirely based on digital communication, including multimedia and hypermedia, which allows the reader to keep track of how to control the order in which information is acquired.

The interdisciplinary nature of distance learning is reflected in the principles of curriculum planning and course development. Distance education aims to meet the needs of the audience, prioritizing the diversity of technologies.

An e-textbook is a textbook based on the use of computer-based teaching methods and the effective use of science-based teaching materials, which provides a great opportunity for students to acquire independent knowledge, as well as distance learning. There are currently 4 categories of etextbooks, the main purpose of which is to:

- new information - the formation of teaching methods, increase the efficiency, quality and productivity of the educational process through the use of modern information and pedagogical, information and computer technologies;

- Modern educational resources in the system of continuing education - the widespread use of etextbooks, in a sense, the organization of their libraries, the introduction of distance learning methods and universal e-learning access to the system.

Development is evolving and changing so fast. Information technology is one of the most important ways to use society's information resources wisely, and it has gone through several stages. The exchange of these stages is determined by the development of scientific and technological progress, the emergence of new technical means of data processing. A person's level of knowledge is also determined by the amount of information that a person learns over a period of time. That is why the effective use of new information technologies is becoming a requirement of today. In particular, there are significant changes in the education system, that is, the distance learning method is used in the education system today. Distance learning is a new form of distance learning. Distance learning is an independent activity. Independent work develops each person's ability to think independently, assess the situation, draw conclusions and make predictions. Today, distance learning is needed to raise the legal awareness of mankind, to increase the rule of law, to apply the law in practice, to make every citizen aware of his rights, to explain the law, ie laws, decisions and decrees to our people, ordinary citizens. creating favorable conditions for the use of new technologies.

An e-textbook, one of the most modern e-learning materials, is a multimedia product that is important for the effective organization of learning in 
independent learning and independent work, and for expanding the creative thinking of the audience. The use of such textbooks in continuous learning mode helps to improve the quality of students' knowledge.

When creating an e-handbook for a subject, a separate portion of the course should include practical (exercises) and control (test questions) sessions, and a large portion of the course should include test sessions and tests. There are several benefits to using an e-learning tool in the learning process:

- The set of information presented in the chosen subject or course has a good structure and describes the completed fragments;

- The structural element of the course consists of hypertext, visual, audio and video commentary or video key topics, and a qualified teacher or speaker expresses his / her views on the subject being taught and is difficult to master in a simple textbook. Explains ideas;

- Uses hypermedia graphics to illustrate complex textbook models and exhibitions in a clear and simple way;

- The electronic manual has a multi-window interface, each window contains interconnected information;

- The text part of the textbook has a large number of intersecting hypertext links, which reduces the time to search for the necessary information, and additional video information or animated clips are fully used to describe the parts of the course that are difficult to describe;

- The electronic manual allows the user to perform actions correctly, the process of obtaining assistance with the use of audio signals, and other forms of information using the capabilities of multimedia;

- demand for information quality, reliability and its structure will increase;

- There is an opportunity to prepare coursework and abstracts with the help of electronic manuals, which can be combined with modern computer and pedagogical technology to create new-look and quality manuals.

Young people are more and more attracted to computers and related issues. Teaching is one of the best ways to handle this. In this way, the teacher does not waste valuable time searching for information in libraries. With the help of a computer, he can easily find the information he needs. It is important to note that the Internet should be sufficient.

It is not easy for any computer or Internet-savvy listener to fully understand what is being written or drawn there. In this regard, it is desirable that the electronic page or training program created on the Internet should be popular, that is, universally understood. Websites are currently written and created in Macromedia FLASH, HTML, Java Script, Macromedia Director methods. Each method has its advantages. If we look at the websites and programs that are created using FLASH, first of all, the time to create them is short and easy.

Enriching the product with various animations, creating convenience and fun for the reader is one of the main goals of the FLASH program. However, it should be noted that the person who creates the product, whether through FLASH or other software, must have sufficient knowledge and imagination in this regard.

The first major for preschool and elementary school teachers is the computer program Word. The second course is Paint Editing, drawing and painting.

The third area of study, the Internet, teaches teachers how to receive and transmit information from the Internet. In addition, the department has developed special programs for in-service training of teachers of specific natural and social sciences. Electronic versions of lecture notes from all disciplines are now available.

\section{Conclusion}

From the above data, it can be concluded that it is difficult to imagine modern information technology and computer life. Every young generation needs to learn how to receive and 
transmit information from the Internet. Admittedly, the interest of young people in reading is declining, and we need to provide e-textbooks with a variety of interesting facts. After all, in order for the student or listener to master this learning material in depth, it is divided into some important theoretical sections, elaborated, all types of lessons are integrated into a single system in terms of content and time, optimized and orientation curriculum, a set of practical training materials, a set of computer-modeled laboratory work, assignments and problems for independent work, guidelines for the implementation and solution of tasks and problems, control questions, tests and their answers, permanent references required for solving problems, an explanatory dictionary of the most commonly used basic concepts and terms in the subject, in the form of references to the literature on this or that issue to divide into parts, to form a set of these parts and thus to organize the mode of indirect dialogue in the learning process, in other words However, the creation of an active environment should be paramount. In this case, the requirements for the educational literature - to provide such requirements as scientific, systematic, clear and fluent presentation of educational material, as well as problem-based learning, recognized as effective pedagogical methods, it is especially important to realize such aspects as the independent work of students and listeners and the organization of collective thinking activities.

\section{References:}

[1] Mirziyoyev Sh.M. We are determined to continue our path of national development step up / Volume 1 / - T .: NMIU of Uzbekistan, 2017.

[2] R.T. Gazieva et al. Automation of technological processes. T .; Znanie, 2004.

[3] Khaydarova, U. (2020). Importance of the new decree on support and promotion of legal education signed during the pandemic. Review of law sciences, volume 2, 2266-268

[4] Toshmatov, O \& Abdijalilovna, D. (2020). Teaching EFL and ESP for Law. Activities and challenges during the covid-19 pandemic in Uzbekistan. Solid State Technology, 63(6), 8318-8325.

[5] Khaydarova, U. (2019). Specific peculiarities of translation in legal documents. Journal of Legal Studies and Research. 5 (5), 157-165

[6] Toshmatov, O \& Yuldashev, O, et.al (2020). IMPACT OF INNOVATIVE MODERN TECHNOLOGY IN TEACHING LANGUAGES IN UZBEKISTAN. Journal of critical reviews, 13(6), 1908-1912.

[7] Khaydarova, U. (2019). Spiritual, social, philosophical and poetic factors of the detective genre. Humanities in the 21st century: scientific problems and searching for effective humanist technologies. 69-72

[8] www.pedagog.uz

[9] www.ziyonet.uz

[10] www.yandex.uz 